\title{
For What Reasons Do Patients File a Complaint? A Retrospective Study on Patient Rights Units' Registries
}

\author{
Gülsüm Önal ${ }^{1}$, M. Murat Civaner ${ }^{2}$ \\ ${ }^{1}$ Clinical Research Ethics Committee, Şişli Etfal Training and Research Hospital, İstanbul, Turkey \\ ${ }^{2}$ Department of Medical Ethics, Uludağ University Faculty of Medicine, Bursa, Turkey
}

Background: In 2004, Patient Rights Units were established in all public hospitals in Turkey to allow patients to voice their complaints about services.

Aims: To determine what violations are reflected into the complaint mechanism, the pattern over time, and patients' expectations of the services.

Study Design: Descriptive study.

Methods: A retrospective study performed using the complaint database of the Istanbul Health Directorate, from 2005 to 2011.

Results: The results indicate that people who are older than 40 years, women, and those with less than high school education are the most common patients in these units. A total of 218,186 complaints were filed. Each year, the number of complaints increased compared to the previous year, and nearly half of the applications were made in 2010 and 2011 (48.9\%). The three most frequent complaints were "not benefiting from services in general" (35.4\%), "not being treated in a respectable manner and in comfortable conditions" (17.8\%), and "not being properly informed" (13.5\%). Two-thirds of the overall applications were found in favour of the patients $(63.3 \%)$, and but this rate has decreased over the years.

Conclusion: Patients would like to be treated in a manner that respects their human dignity. Educating healthcare workers on communication skills might be a useful initiative. More importantly, health policies and the organisation of services should prioritise patient rights. It is only then would be possible to exercise patient rights in reality.

Keywords: Communication, health services administration, medical ethics, quality improvement, patient rights
Historically, the development of patient rights began to emerge in the 1970s and moved into the international arena in the 1980s. Countries developed the strength of declarations in 1990s, and legal regulations shaped the practical implications in the 2000s. In the 2010s, it is widely accepted that it is important to create and improve ways for patients to express their thoughts, feelings, and complaints. Legislation on patient rights in Turkey has followed global trends. "The Regulation of Patient Rights", organising basic concepts, principles, and outlining patient rights, were prepared based on the interna- tional documents and were issued in 1998 (1). Patient rights were included in medical education, patient rights organisations have been founded, and allegations of patient rights violations have started to appear in the media more than ever before.

The Ministry of Health $(\mathrm{MoH})$ issued the directive entitled "Practice of Patient Rights in Healthcare Facilities" in 2003, aiming to increase the recognition of rights and their implementation into services (2). This directive describes the mechanisms of the complaint procedure in the event of a violation 
of rights. The document also defines the structure and duties of the newly created Patient Rights Unit and Patient Rights Board. The Patient Rights Unit (PRU) and the Patient Rights Board (PRB) have a particular importance in the complaint mechanism. They are the foundations of the application system and the organs for the evaluation of any alleged incident. The Unit Officer, the first officer who meets the patient, is a healthcare worker (social worker, psychologist, nurse, etc.), and starts to work after receiving compliance training on public relations. If the problem cannot be resolved by oral communication at PRU, then the patient files a written complaint and the case is referred to the PRB. The PRB is chaired by the Vice-Chief of the hospital, who is in charge of hospital quality services. The PRB consists of a PRU Officer, the chief of the accused department, a representative of a non-governmental organisation working in the field of patient rights (if needed), the patient's attorney, a union representative authorised by the institution, a citizen, and a member of the city council appointed by the city Governor. The PRBs do not have any power of sanctions; the file is referred to the administration of the hospital for disciplinary interrogation if necessary.

The healthcare system in general, which was believed to have permanently settled patient rights, needs to deepen its understanding of the patients' specific needs. Investigating patients' complaints provides a unique opportunity to improve the quality of healthcare services. However, there is a gap of knowledge in the literature regarding patient rights in Turkey and the violations that have been investigated. The examination of the applications made to the PRUs can be helpful in learning the priorities and needs of patients. To determine which patient rights are being violated, the applications' pattern over the years, the share of communication problems in the applications, and patients' expectations of the services may contribute to responding to these questions and to the ongoing scientific debate. Accordingly, we present a research evaluating the applications to PRUs.

\section{MATERIALS AND METHODS}

This retrospective study, which was performed from 2005 to 2011 in 54 public hospitals operating under the authority of the Istanbul Health Directorate, examined the registries of written and oral applications made to PRUs in these health facilities. Istanbul, Turkey's largest metropolis, in which $18.2 \%$ of the country's population resides, is home to many different classes, ethnicities, religions and cultures; therefore, Istanbul's patient rights complaint data can be considered representative of the country.

In this study, the registry database of the Istanbul Provincial Directorate of Patient Rights was searched, which includes age, gender and education level of the complainant,
TABLE 1. Demographic characteristics of the applicants (\%)

$\%$

\begin{tabular}{lc}
\hline Gender (n: 206, 175) & \\
Female & 52.7 \\
Male & 47.3 \\
Total & 100.0 \\
Age group (n: 205, 229) & \\
41 and above & 45.2 \\
$36-40$ & 14.3 \\
$31-35$ & 13.8 \\
25 and below & 13.5 \\
$26-30$ & 13.2 \\
Total & 100.0 \\
Education (n:203, 526) & \\
Elementary and secondary & 53.6 \\
High school & 25.0 \\
University and higher & 10.2 \\
Illiterate & 8.2 \\
Total & 100.0
\end{tabular}

occupation and unit of the healthcare worker sued, the type of the hospital (Training and Research Hospital or State Hospital), the type of violation, how the complaint was handled (resolved in PRU, or referred to PRB), and the results of the complaint. There was no personal patient information in the database. Official permission of the Istanbul Health Directorate and approval of İstanbul Şişli Etfal Hospital's Ethics Committee were granted. Chi-square test was used for statistical analysis, in order to determine whether there are any significant changes over the years and also to compare data to that of the general population of Turkey.

It is easy to predict that not all violations convert into applications. The impossibility of determining the actual number of rights violations on the basis of the number of applications is a limitation. Therefore, we would rather have the opportunity to observe the conditions under which people file a complaint and the distribution of the applications. The data recording system was established in 2004, but the irregularities with the registry made the first year ineligible for this study.

\section{RESULTS}

\section{Characteristics of the applicants}

Following investigation of the seven-year period application data, the demographic characteristics of the patients are shown in Table 1.

Female patients were found to have a slightly higher proportion of applications than males in PRUs (52.7\%). Upon com- 
paring this distribution to the gender distribution of Istanbul's population during the studied period, it was determined that the difference is statistically significant $(p<0.000)$. In other words, gender was a determinant for applications to PRUs.

Almost half of the applicants were 41 years old or older (45.2\%). Upon comparison with the age distribution of Istanbul's population for the same period, highly significant statistical differences were revealed $(\mathrm{p}<0.000)$. In other words, people over the age of 40 years complained more frequently than those in any other age group. Additionally, the complaint rate increased with age.

More than half $(53.6 \%)$ of the applicants were graduates of elementary and secondary school (combined total of eight years of education, with five years for elementary school and three years for secondary being obligatory in Turkey). Upon comparison with Istanbul's population education level during the studied period, we found that patients with less than high school level education made more complaints than any other education group $(\mathrm{p}<0.000)$. Patients who were illiterate had the lowest complaint rate $(8.2 \%)$.

\section{Changes in the number of applications}

During the examination period, a total of 218,186 applications were submitted to the PRUs in Istanbul. To calculate the ratio of the applications, data from the Turkish Institute for Statistics and MoH for 2008 to 2011 were used $(3,4)$. According to the $\mathrm{MoH}$ database, in 2008, there were 1.38 visits per person to $\mathrm{MoH}$ hospitals located in Istanbul, 1.55 in 2009, 1.72 in 2010, and 3.2 in 2011. When these data are taken into consideration with respect to the population of Istanbul during those years, an average of $25,643,876$ hospital visits was calculated. An average of 44,107 applications were submitted to the PRUs in the same period of time, and by comparing this number to the total number of hospital visits, the complaint rate was calculated to be 1.72 per 1,000 .

Upon examining the annual distribution of applications made to PRUs, each year investigated showed a significant increase compared to the previous year (average increase: $44.5 \%$ ). Nearly half of the applications were made in 2010 and 2011 (48.9\%). In addition, while the population of Istanbul had increased by $7.3 \%$ in the $2008-2011$ period, and applications made to $\mathrm{MoH}$ hospitals increased by $141 \%$, complaints filed at the PRUs increased by $222.3 \%$. The complaints per hospital also increased by $83.9 \%$ in the period from 2008-2011.

Distribution with respect to institution, unit and position

Many of the applications were made in training and research hospitals (60.7\%), while $39.3 \%$ of complaints occurred in state hospitals $(\mathrm{p}<0.000)$. The complaints were distributed by healthcare workers as follows: $34.5 \%$ for specialist physicians, $16.5 \%$ for administrative staff, $11.4 \%$ for residents,
TABLE 2. Distribution of complaint reasonsa (\%)

\begin{tabular}{lc}
\hline & $\%$ \\
\hline Not benefiting from services in general & 35.4 \\
Not being treated in a respectable manner and in & 17.8 \\
comfortable conditions & \\
Not being properly informed & 13.5 \\
Cannot use the right to choose and change providers & 5.2 \\
Safety issues & 1.6 \\
Violation of privacy & 1.0 \\
Not asked for informed consent & 0.8 \\
Problems related to visitors or the accompanying person & 0.4 \\
Cannot practice religious faith & 0.2 \\
Cannot exercise the right to apply to the hospital services & 0.2 \\
Other complaints & 23.9 \\
Total & 100.0 \\
\hline
\end{tabular}

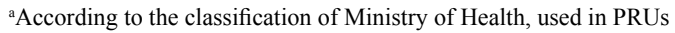

$8.5 \%$ for dentists, $5.2 \%$ for nurses, $0.9 \%$ for the vice-chief of the hospital and $0.6 \%$ for the chief the hospital. A classification of "other" was reported for $20.3 \%$ of the complaints, which included public relations personnel, secretaries, computer operators, cleaning staff, and security staff. By units, complaints most commonly occurred in polyclinics (47.4\%), with $8.9 \%$ in laboratory and imaging units, $7.5 \%$ in clinics, $6.6 \%$ in emergency services and $5.7 \%$ in administrative services.

\section{Reasons for complaints to Patients' Rights Units}

The top three complaints, shown in Table 2, were "not benefiting from services in general", "not being treated in a respectable manner and in comfortable conditions", and "not being properly informed" during the visit.

Complaints such as asking for the location of a certain unit in the hospital, requesting an appointment, requesting an ambulance for transportation of a discharged patient, or "workers with a frowny face" were labelled as "other" complaints in the registration system. Excluding the "other" from the total, the three most frequent complaints comprise approximately two-thirds of the total (66.8\%). These complaints are always in the same order as the top-three over the years. In addition, the increased levels of complaint rate per hospital for those top-three complaints were $195.4 \%$ for "not being treated in a respectable manner and in comfortable conditions", $73.8 \%$ for "not benefiting from the services in general", and $22.9 \%$ for "not being properly informed".

Applications were composed of $90.7 \%$ verbal (resolved "on-site") and 9.3\% written complaints (resolved in PRBs). Two-thirds of the applications were found in favour of patients $(63.3 \%)$. This rate increased until the 2008 , to $71.9 \%$, and then decreased in the following years (the rate was calculated by 
adjusting the percentage, as some of the complaints were still not concluded). In 2011, more than half of the applications were found in favour of healthcare workers for the first time $(55.7 \%)$. A similar trend was found to exist for on-site solutions, which were increasingly found in favour of the patients until 2008 (79.6\%), but then showed a decrease to $54.5 \%$ in 2011. However, in PRBs, the percentage of complaints found in favour of patients steadily decreased over the years, from $54.4 \%$ in 2005 to $18.9 \%$ in 2011 .

\section{DISCUSSION}

\section{Characteristics of the applicants}

The findings indicate that individuals older than 40, women, and those who graduated from elementary and secondary school submit the most complaints to PRUs. The applications to PRUs were mostly made by women. This finding is consistent with similar studies in other countries (5-9). The reason why women complain more frequently to PRUs is unknown as very few previous studies have been conducted on this topic. In some studies, women scored lower on patient rights than men (10), while they scored higher in other studies (11). A possible explanation might be that women have suffered through a work division based on societal gender roles, and women typically carry the burden of care. In addition, the participation rate of women in the labour force in Turkey is far lower than the world average and only slightly higher than that of the Middle East and North African countries (12). Women's lack of employment and gender inequality indicate that they take on more responsibility in caring for ill family members in the hospital.

Compared to the distribution among the general population, patients over 40 years of age complained most often. In fact, half of the applicants were over the age of 40 , which is consistent with other studies in the literature (13-15). It is generally assumed that an increased awareness of advocacy comes with aging and maturing. Additionally, the fear of not being served due to a complaint at a "government office" might decrease with age. However, the high proportion of those aged 41 and older and their reasons for complaining should be explored in future studies.

When the results are reviewed according to education level, those individuals who were illiterate had the lowest complaint rate, perhaps due to a low level of awareness of patient rights. However, no linear relationship was found between education level and complaint rate. This fluctuating pattern may be due to the education level profile of Turkey, as the majority of the population graduate from elementary and secondary school. In addition, a higher education level may increase people's awareness of patient rights, but may also cause patients to believe that the mechanism of patient rights is insufficient or useless.

\section{Complaint frequency over the years}

The ratio of compliant applications was approximately 1.72 per thousand, which is consistent with results in the literature. Extensive research showed that the rate in 67 hospitals in Australia was 1.42 in every thousand (16), and other reported rates were 1.12 in a large public hospital (17), 2.7 in emergency services (8), and 1.17 in Singapore (6). A similar study conducted in a small city in Turkey investigating complaints from 2004 to 2008 showed that the written application ratio was 0.21 per thousand, and the ratio of oral applications was 1.4 (18). When the seven years of data were taken into consideration, it was possible to state that the results were similar to those applications in different cultures, healthcare systems, economic levels and education levels of other countries. However, it would be misleading to say that this ratio proves that patients are satisfied with the quality of healthcare services and that all patient rights are exercised fully, as PRUs in Turkey are relatively new compared to in other countries, and/or patients simply may not be aware of their rights. In addition, patients might not want to make a formal complaint and may hold back their complaints believing that they will not get an appropriate resolution or that they will be treated worse because of their complaint. Also, some patients may simply find it sufficient to have their complaints settled with an apology or a simple explanation. For all of these reasons, it is not possible to claim that the number of applications reflects the actual number of violations of patient rights. Qualitative researches are needed to gain an understanding of the determinants and circumstances that influence the decision to use the complaint mechanism.

However, complaints have increased over the years compared to the previous years, and the increased rate is much higher than the increase in the population and the number of hospital visits. In addition, nearly half of the applications were submitted within the past two years. Similarly, in a study conducted in Edirne, Turkey between 2004 and 2008, oral complaints increased by $102.2 \%$ and written complaints by $97.8 \%$ (18). The increasing number of applications over time may be related to the increased awareness of patient rights, and improved legal regulations regarding these rights. Complaints are filed more often when new laws are issued, as shown in a university hospital in France (1998-2000), where a study was performed to determine the effects of a specific legal regulation on patient rights (19). Nevertheless, considering the distribution of the complaints, it was revealed that classical patient rights, such as informed consent, confidentiality and privacy, comprise only $1 \%$ of all complaints, which suggests that the increased awareness may not be the main explanation. The significant increase in complaints can also be linked to other factors. For example, the quality of services might have been worsening over the years. Examin- 
ing the reasons for complaints may give a clearer picture of the possible relationships between the quality of services and the complaint rate.

\section{Reasons for complaints}

The three most frequent reasons for complaint have remained the same over the years studied here and across institutions, and have increased at very high rates; the complaint "Not being treated in a respectable manner" increased by $195.4 \%$, for instance. This indicates that these problems systematically exist in healthcare services, and the expectations of patients and their relatives are chronically left unmet regarding these complaints. Patients usually do not complain about the violation of classical patient rights, such as confidentiality, consent, or access to services needed. Rather, the most frequent complaints in Turkey and in the world are usually linked to expectations related to human dignity, such as being treated in a respectable manner and being properly informed. In the literature, countries with different healthcare systems, such as the USA $(20,21)$, Singapore $(6,7,15)$, the UK $(14,22,23)$, and Australia $(9,16)$, all seem to have the same three most frequent complaints. Studies conducted in 2007 in a heart hospital in Tehran (24), in an education hospital of Taiwan in 2010 (25) and in four large state hospitals in Canada (5) in 2005 , showed that the primary complaint was "humanitarian/respectable approach and communication problems". Vinen's study (26) determined that patients' expectations are the following (especially in emergency departments): "reliability, empathy, responsiveness, cleanliness, comfort and a stimulating environment, assurance to feel safe and secure, quality service, and communication". Therefore, explaining the dynamics behind the problems related to communication appears to be important. We believe that health policies might provide a concrete answer. In the case of Turkey, a healthcare reform project of the World Bank titled "Transformation of Health Program" has been being implemented for more than a decade. The project aims to gradually establish the steps of privatisation in healthcare services, asserting that privatisation provides more efficiency and quality in services. However, by implementing a business approach and measures into medicine, patient rights are significantly restricted by positioning them as customer rights in the recently-established healthcare market, while the complaint mechanisms hold the individual healthcare worker responsible for every type of incident. Due to the performance-based incentive system, the time allocated per patient has decreased, and establishing healthy communication and a trust-based relationship is becoming more difficult, while the possibility of making a mistake is increasing. These phenomena may reduce patient satisfaction and access to health services, resulting in more complaints. The pressure caused by those policies may create tension and a counter-reaction among providers against patients who have become potential complainers in their eyes. These conditions may explain that one of the main reasons for "communication problems" is the approach deliberately chosen by health policies aiming at commodification of services. In addition, our study found that $90.7 \%$ of the applications were resolved "onsite" in PRUs, and the percentage of complaints resolved in favour of healthcare workers has been steadily increasing over the years in PRBs. There are similar findings in the literature showing that $33.7 \%$ of the complaints were valid, while the remainder are about service standards, and half of the complaints about the organisation or infrastructure were labelled as unmerited (7). Although these findings might suggest the possibility of an increase in unjustified complaints, we think that they support the suggestion that communication problems are basically system-derived.

The patient complaint rate in Turkey is no higher than the rates in other countries. However, we could not conclude that patients fully exercise their rights. Although complaints about informed consent or confidentiality are much lower than those regarding other issues, violations of classical patient rights might be underreported. Patients do not complain very often because they are unaware of their rights, as shown by previous studies. However, the complaint rate was increased two-fold compared to the increase in the total number of hospital visits. This increase may be linked to an increase in the knowledge of rights and right-seeking attitude and/or due to an increase in violations caused by organisational problems. This issue must be investigated further. At this point, the following questions remain: To what extent does seeking patient rights garner the attention of workers, administrators, and policy makers? Do PRUs provide a platform for patients to seek their rights? Additionally, studies about the operation procedures of the complaint system, assessing written complaints, whether the PRUs and PRBs make their decisions objectively, whether patients, hospital administrators, politicians and the media use this mechanism as a "pressure tool" against healthcare workers, and suggestions of patients and healthcare workers are needed.

Patients would like to be treated in a manner that respects their human dignity. They would like to be safe and have confidence in the healthcare institution while seeking medical attention in an unfamiliar environment. Establishing healthy communication is of paramount importance, as it seems that this component is the key to patient satisfaction. In fact, communication problems are usually resolved and compensated for relatively easily. Studies show that a simple explanation and a verbal apology resolved most of the complaints $(6,16$, 24 ), and patients believe that a dialogue between parties is necessary for revealing accurate information (27). Educating healthcare workers on communication skills might be a useful 
initiative in that sense. Moreover, healthcare workers should be aware of the determinants of problems regarding patient rights and should direct their reactions and demands to policymakers and decision-makers, instead of holding patients responsible. Nevertheless, before anything else, health policies and the organisation of services should prioritise patient rights.

Ethics Committee Approval: Ethics committee approval was received for this study from the ethics committee of Şişli Etfal Hospital.

\section{Informed Consent: N/A.}

Peer-review: Externally peer-reviewed.

Author contributions: Concept - G.Ö., M.M.C.; Design - G.Ö., M.M.C.; Supervision - G.Ö., M.M.C. Resource - G.Ö.; Data Collection\&/or Processing - G.Ö.; Analysis\&/or Interpretation - G.Ö., M.M.C.; Literature Search - G.Ö., M.M.C.; Writing - G.Ö., M.M.C.; Critical Reviews - G.Ö., M.M.C.

Conflict of Interest: The first author (GO) was working as the Patient Rights City Coordinator of Istanbul Health Directorate during the study period.

Financial Disclosure: The authors declared that this study has received no financial support.

\section{REFERENCES}

1. The Regulation of Patient Rights. Issued by Republic of Turkey Ministry of Health. Official Gazzette, Aug 1, 1998.

2. Practice of patient rights in healthcare facilities. Issued by Republic of Turkey Ministry of Health, 2003.

3. Turkish Institute for Statistics. Available from: http://www.tuik. gov.tr/Start.do

4. Republic of Turkey, Ministry of Health. Annual Health Statistics. 2008, 2009, 2010, 2011. Available from: http://www.saglik. gov.tr

5. Kline TJ, Willness C, Ghali WA. Predicting patient complaints in hospital settings. Qual Saf Health Care 2008;17:346-50. [CrossRef]

6. Wong LL, Ooi S, Goh LG. Patients' complaints in a hospital emergency department in Singapore. Singapore Med J 2007;48:990-5.

7. Ooi SB. Emergency department complaints: a ten-year review. Singapore Med J 1997;38:102-7.

8. Taylor DM, Wolfe R, Cameron PA. Complaints from emergency department patients largely result from treatment and communication problems. Emergency Medicine (Fremantle) 2002;14:43-9. [CrossRef]

9. Daniel A, Burn R, Horarik S. Patients' complaints about medical practice. Med J Aust 1999;170:598-602.

10. Ozer N, Karaman OZ, Saritas S. Do patients treated in surgical clinics know their rights? Ataturk Universitesi Hemsirelik Yuksekokulu Dergisi 2009;12:19-28.

11. Eksen M, Karadag N, Isikay C, et al. Determining the level of knowledge of patients on patient rights. IJHS 2004;1:2-13.

12. Karabiyik I. Women employment in working life of Turkey. Marmara Universitesi IIBF Dergisi 2012;32:231-60.

13. Jimenez-Corona ME, Ponce-De-Leon-Rosales S, Rangel-Frausto S, Mohar-Betancourt A. Epidemiology of medical complaints in Mexico: identifying a general profile. Int Journal for Qual in Health Care 2006;18:220-23. [CrossRef]

14. Webb B. A study of complaints by patients of different age groups in an NHS trust. Nurs Stand 1995;9:34-7.

15. Lim HC, Tan CB, Goh LG, Ling SL. Why do patients complain? A primary health care study. Singapore Med J 1998;39:390-5.

16. Taylor DM, Wolfe RS, Cameron PA. Analysis of complaints lodged by patients attending Victorian hospitals, 1997-2001. Med J Aust 2004;181:31-5.

17. Anderson K, Allan D, Finucane P. A 30-month study of patient complaints at a major Australian hospital. J Qual Clin Pract 2001;21:109-1. [CrossRef]

18. Saracoglu GV, Tokuc B, Guler F, Gül H. Evaluation of patient rights practices in a developing country: the Edirne model for the implementation of patient rights in Turkey. $J$ Med Ethics 2010;36:488-93. [CrossRef]

19. Giugliani C, Gault N, Fares V, Jegu J, Trolli SE, Biga J, et al. Evolution of patients' complaints in a French university hospital: is there a contribution of a law regarding patients' rights? BMC Health Serv Res 2009;9:141-50. [CrossRef]

20. Curka PA, Pepe PE, Zachariah BS. Incidence, Source, and nature of complaints received in a large, urban emergency medical services system. Acad Emerg Med 1995;2:508-12. [CrossRef]

21. Wofford MM, Wofford JL, Bothra J, Kendrick SB, Smith A, Lichstein PR. Patient complaints about physician behaviours: a qualitative study. Acad Med 2004;79:134-8. [CrossRef]

22. Bark P, Vincent C, Jones A, Savory J. Clinical complaints: A means of improving quality of care. Qual Health Care 1994;3:123-32. [CrossRef]

23. Hunt MT, Glucksman ME. A review of 7 years of complaints in an inner-city Accident and Emergency Department. Arch Emerg Med 1991;8:17-23. [CrossRef]

24. Manouchehri Moghadam J, Ibrahimipour H, Sari Akbari A, Farahbakhsh M, Khoshgoftar Z. Study of patient complaints reported over 30 months at a large heart centre in Tehran. Qual Saf Health Care 2010;19:e28.

25. Hsieh SY. The use of patient complaints to drive quality improvement: an exploratory study in Taiwan. Health Serv Manage Res 2010;23:5-11. [CrossRef]

26. Vinen J. Doctors beware: why a patient complains is not always what it seems. Emerg Med (Fremantle) 2002;14:9-11. [CrossRef]

27. Quinche F. Textual analysis of patients' complaints in the hospital milieu. Rev Med Suisse Romande 2001;121:837-43. 